\title{
Computerized Dynamic Posturography in Patients with Diabetic Peripheral Neuropathy and Visual Feedback-Based Balance Training Effects
}

\author{
Mohieldin M. Ahmed ${ }^{1 *}$, Douaa M. Mosalem², Wafaa A. Tarshouby ${ }^{2}$, Aziz K. Alfeeli ${ }^{1}$, Ayyoub B. Baqer ${ }^{3}$, Mohamed H. \\ Mohamed ${ }^{1}$ \\ ${ }^{1}$ Amiri Hospital, Ministry of Health, Kuwait; ${ }^{2}$ Physical Medicine and Rehabilitation Hospital, Ministry of Health, Kuwait; \\ ${ }^{3}$ Farwania Hospital, Ministry of Health, Kuwait
}

\author{
Citation: Ahmed MM, Mosalem DM, Tarshouby \\ WA, Alfeeli AK, Baqer AB, Mohamed MH. \\ Computerized Dynamic Posturography in \\ Patients with Diabetic Peripheral Neuropathy \\ and Visual Feedback-Based Balance Training \\ Effects. OA Maced J Med Sci. 2014 Jun 15; \\ 2(2):271-276. \\ http://dx.doi.org/10.3889/oamjms.2014.045 \\ Key words: Diabetic peripheral neuropathy \\ (DPN); sensory organization test (SOT) \\ composite equilibrium score (CES) \\ somatosensory ratio score; Visual Feedback- \\ Based Balance Training. \\ "Correspondence: Dr. Mohieldin M. Ahmed. \\ Head of Physical Medicine and Rehabilitation \\ Head of Physical Medicine and Rehabiltation \\ Hospital. E-mail: drmohyahmed@gmail.com \\ Received: 31-Jan-2014; Revised: 21-Mar- \\ 2014; Accepted: 29-Apr-2014; Online first: \\ 26-May-2014 \\ Copyright: (๑) 2014 Ahmed et al. This is an \\ open access article distributed under the terms \\ of the Creative Commons Attribution License, \\ which permits unrestricted use, distribution, \\ and reproduction in any medium, provided the \\ original author and source are credited. \\ Competing Interests: The authors have \\ declared that no competing interests exist.
}

\begin{abstract}
BACKGROUND: Diabetic peripheral neuropathy (DPN) often has reduced stability during standing conditions.

AIM: To compare balance control in diabetic patients and normal subjects using computerized dynamic posturography and to assess effect of visual feedback-based balance training in DPN.

MATERIALS AND METHODS: A total of 57 patients of type 2 diabetes mellitus and 30 agematched normal control subjects were recruited. The sensory organization test was done before and after the training program.

RESULTS: There was a significant decrease of mean $( \pm S D)$ of composite equilibrium score and somatosensory ratio score between subgroups of DPN and control healthy group $(p<0.05)$. There was a significant increase of mean $( \pm S D$ ) of composite equilibrium score and the somatosensory ratio score after treatment as compared to results before training $(\mathrm{p}<0.05)$ in mild DPN. Moreover, there were a significant correlation between composite equilibrium score and disease duration before training in the severe DPN $(r=0.368, p<0.05)$.

CONCLUSIONS: Computerized dynamic posturography is an important quantitative tool in the assessment of posture instability and allows for early disclosure of the failure of the postural control system. Visual feedback-based balance training was shown to be a promising method for fall prevention among early diabetes mellitus with peripheral neuropathy.
\end{abstract}

\section{Introduction}

Diabetic peripheral neuropathy (DPN) is a common disorder affecting more than 100 million people worldwide with diabetes and is the most common form of peripheral neuropathy. DPN affects greater than half of diabetic patients with a history of more than 25 years of diabetes [1, 2]. The definition of DPN for clinical practice is "the presence of symptoms and/or signs of peripheral nerve dysfunction in people with diabetes after the exclusion of other causes [3]. There are various risk factors that have been linked with DPN including height, weight, gender, age, disease duration, glycemic control, high blood pressure, tobacco use, alcohol use, and lipids. The pathogenesis of DPN is multifactorial with the main categories being metabolic and ischemic factors [4]

The most prevalent syndrome of patients suffering from diabetic neuropathy is distal symmetric, primarily sensory, peripheral polyneuropathy as a result of progressive nerve fiber loss which manifests as a reduction of nerve conduction velocity [5]. It is well established that proprioceptive information from the lower extremities is one of the main input sources (besides the visual and labyrinthine senses), that ensure and regulate postural control. As diabetic neuropathy is intimately linked with considerable restriction in this sensory modality, disturbances of postural control are a frequent, clinically well-known symptom of the diabetic patient, actually labeled by some authors as "sensory ataxia" [6]. 
Patients with diabetic polyneuropathy often have reduced stability during standing and walking conditions, difficulties in walking on rough ground or more pronounced balance problems. With respect to falls, a number of recent reports suggest that type 2 diabetes mellitus is associated with increased risk of falls [7]. The functional performance can be measured by posturography. Static posturography has revealed a less stable posture of diabetic patients with peripheral neuropathy. However it does not discriminate the effect of altered somatosensory system from visual and vestibular information [8].

The sensory organization test is a component of computerized dynamic posturography device that evaluates the impact of visual, vestibular, and somatosensory inputs, as well as sensory reweighting, under conditions of sensory conflict [7]. It provides information about the integration of multiple components of balance, it leads to an outcome measure called the "composite equilibrium score" (CES), which reflects the overall coordination of the visual, proprioceptive and vestibular systems for maintaining standing posture [5].

The computerized dynamic posturography, in addition to more traditional methods, such as nerve conduction velocity, may help to investigate disturbances in balance in diabetic patients with peripheral neuropathy. It provides testing of the three sensory modalities, involved in the maintenance of balance i.e. vestibular, visual and somatosensory systems [7].

The aim of this study was to compare balance control in type 2 diabetic patients with or without peripheral neuropathy and age-matched neurologically normal subjects using computerized dynamic posturography; as well as to assess balance control before and after training in patients with diabetic peripheral neuropathy; moreover, to explore the correlation of balance control with the severity of neuropathy (mild, moderate, severe and absent neuropathy) and their risk factors including age and disease duration.

\section{Subjects and Methods}

A total of 57 patients of type 2 diabetes mellitus (17 with mild DPN, 13 with moderate DPN, 11 with severe DPN and 16 diabetic patients without peripheral neuropathy) and 30 age-matched normal healthy control subjects were recruited for this study. The patients of type 2 diabetes mellitus were 30 men and 17 women, with mean (SD \pm ) of age $49.38 \pm 5.12$ years, disease duration $12.91 \pm 6.99$ years, body mass index $22.51 \pm 2.02 \mathrm{~kg} / \mathrm{m}^{2}$, fasting blood sugar $7.85 \pm 1.13 \mathrm{mmol} / \mathrm{L}$ and $\mathrm{HbA} 1 \mathrm{c} 7.48 \pm 0.65 \%$. All patients were evaluated clinically with a brief neurological examination. All patients underwent EMG and NCV to confirm or exclude DPN.
The diabetics patients were divided into four subgroups according to criteria of Dyck et al. [9], the $1^{\text {st }}$ subgroup $(A)(n=16)$ absent peripheral neuropathy (DPN), the $2^{\text {nd }}$ subgroup (B) $(n=17)$ has mild DPN, the $3^{\text {rd }}$ subgroup $(C)(n=13)$ has moderate DPN and the $4^{\text {th }}$ subgroup (D) $(n=11)$ has severe DPN. The method of staging of the diabetic neuropathy was based on the simple staging approach recently proposed by Dyck et al., using the following criteria: NO, absent neuropathy; MILD N1, asymptomatic neuropathy; MODERATE 2a, symptomatic neuropathy; and SEVERE 2b, symptomatic neuropathy, characterized by disabling symptoms and history of ulcer [9].

Inclusion criteria of our patients included: (1) the ambulatory patients with ability to ambulate $25 \mathrm{ft}$ independently; (2) a known history of diabetes mellitus treated by diet, oral hypoglycemic, or insulin therapy ; (3) lower extremity symptoms consistent with PN; (4) willingness to participate in the study; and (5) conclusive electrodiagnostic evidence of peripheral neuropathy which was diagnosed by Hoffmann's reflex and a Nihon-Kohden Neuropack $\circledast$ electromyography which the test evaluates the latency and amplitude of the response of a peripheral nerve to an electrical stimulus of increasing intensity applied to the tibial nerve for the detection of peripheral neuropathy" [10].

The exclusion criteria included those with vestibular abnormalities; those with nephropathy and retinopathy; those with a history of antihypertensive medication that might produce postural hypotension, high blood pressure or drug intake (tobacco or alcohol use) that affect postural stability; those with musculoskeletal disorders that contribute to postural instability; those with peripheral arterial disease by measured by ABPI; and those with cardiac, renal and liver diseases and. Postural hypotension, also known as orthostatic hypotension, is a form of hypotension in which a person's blood pressure suddenly falls when standing up. The patients gave their informed voluntary consent to participate in the study according to the protocol approved by the local ethics committee and in accordance with the ethical standards of the Helsinki declaration.

Fasting venous samples were collected for the estimation of blood sugar, liver and renal functions. The $\mathrm{HbA} 1 \mathrm{c}$ level was measured using highperformance liquid chromatography instruments (HLC-723 GHB Ills; Tosoh Corporation, Tokyo, Japan) with a reference range of $4.5 \%-6.2 \%$. Blood glucose was measured before performing the tests to rule out hypoglycemia.

All patients were evaluated for postural stability using computerized dynamic posturography device. The SMART Balance Master (NeuroCom International Inc, Clackamas, OR, USA) was used for the postural stability assessment. 
The sensory organization test (SOT) is a component of computerized dynamic posturography device which included six test conditions which lasting 20 seconds each, and repeated three times to get stable values. The first three conditions include SOT 1 (eyes open), SOT 2 (eyes closed), SOT 3 (swayreferenced vision with standing on a fixed platform called static posturography. The second three conditions include SOT 4 (eyes open), SOT 5 (eyes closed), SOT 6 (sway-referenced vision with standing on a moving platform called dynamic posturography. Composite equilibrium score (CES \%) was calculated that describes the overall level of performance under the six conditions. Scores range from 0 to 100 , with 0 representing a fall and 100 representing perfect stability [11].

The sensory analysis scores (SA) represent the influence of each sensory system on the individual's stability, and quantify the relative difference in scores between conditions. The somatosensory ratio compares condition 2 to condition 1 and measures postural stability when vision is removed. The visual ratio compares condition 4 to condition 1 and measures the ability of the visual system to function when somatosensory input is altered by sway-referencing. The vestibular ratio compares condition 5 to condition 1, assessing the stability of the individual when both somatosensory and visual input have been altered by swayreferencing or eye closure, respectively. A vision preference score, an indication of whether the participant is overly reliant on visual information, is also calculated using the ratio of the sum of conditions 3 and 6 to the sum of conditions 2 and 5 [11].

All patients received complex training course for three months including visual feedback balance training (twice weekly) by using computerized dynamic posturography and conventional physical therapy (three times weekly). In balance exercises with with visual feedback balance training, group received information about their centre of gravity position as they shifted their weight during various activities. In balance exercises with the conventional therapy, group received verbal and tactile cues to encourage symmetrical stance and weight shifting. All patients were evaluated by the study of postural stability by computerized dynamic posturography device before and three months after the training program.

\section{Statistical analysis}

We used SPSS (Statistical Package from Social Science Program) version 15 for data processing. Quantitative data were presented as mean $( \pm S D)$. Statistical evaluation of the data was performed with one-way analysis of variance (ANOVA) test for multiple comparisons between subgroups of diabetic peripheral neuropathy patients. Findings with an error probability value of less than
0.05 were considered as statistically significant, that of less than 0.001 were considered as highly significant. Correlation between variables was done and Pearson correlation coefficient was calculated. All tests were 2tailed and considered statistically significant at $p<$ 0.05 .

\section{Results}

Clinical characteristics of diabetic patients and control group are shown in Table 1.

Table 1: Clinical characteristics of diabetic patients and control group.

\begin{tabular}{|c|c|c|}
\hline Data & $\begin{array}{l}\text { Type } 2 \text { diabetic } \\
\text { Patients }(n=57)\end{array}$ & $\begin{array}{l}\text { Control } \\
(n=30)\end{array}$ \\
\hline Age (years) & $49.38 \pm 5.12$ & $\begin{array}{l}45.16 \pm 2.26 \\
(p>0.05)\end{array}$ \\
\hline $\begin{array}{l}\text { Gender (male/female) } \\
\text { Disease duration (years) }\end{array}$ & $\begin{array}{c}30 / 27 \\
12.91 \pm 6.99\end{array}$ & $20 / 10$ \\
\hline Body mass index $\left(\mathrm{kg} / \mathrm{m}^{2}\right)$ & $21.51 \pm 2.02$ & $\begin{array}{c}21.77 \pm 2.62 \\
(p>0.05)\end{array}$ \\
\hline Frequency of falls in previous 6 months. & $\begin{array}{l}<3 \text { fall }(n=15) \\
>3 \text { times }(n=7)\end{array}$ & - \\
\hline $\begin{array}{l}\text { Therapy (diet/oral hypoglycemic drugs) } \\
\text { Total number for diabetic subgroups: } \\
\text { Subgroup } A=D M \text { absent neuropathy } \\
\text { Subgroup } B=\text { mild peripheral neuropathy } \\
\text { Subgroup } C=\text { moderate peripheral } \\
\text { neuropathy } \\
\text { Subgroup } D=\text { severe peripheral } \\
\text { neuropathy }\end{array}$ & $\begin{array}{c}57 / 44 \\
- \\
n=16 \\
n=17 \\
n=13 \\
n=11\end{array}$ & $\begin{array}{l}- \\
- \\
- \\
- \\
-\end{array}$ \\
\hline Fasting blood sugar(mmol/l) & $7.85 \pm 1.13$ & $\begin{array}{l}4.6 \pm 1.31 \\
(p>0.05)\end{array}$ \\
\hline $\mathrm{HbA1c}(\%)$ & $7.24 \pm 1.17$ & $\begin{array}{c}4.08 \pm 0.50 \\
(p>0.05)\end{array}$ \\
\hline S. Creatinine (umol/l) & $112.3 \pm 6.11$ & $\begin{array}{l}80.5 \pm 7.6 \\
(p>0.05)\end{array}$ \\
\hline
\end{tabular}

In Table 2, there was non-significant differences of mean ( \pm SD) of composite equilibrium score, somatosensory ratio score, visual ratio score and vestibular ratio between diabetes without PN and control healthy group $(p>0.05)$. However, there was a significant decrease of mean ( \pm SD) of composite equilibrium score and somatosensory ratio score between mild DPN and control healthy group ( $p$ $<0.05$ ). Moreover, there was a statistical significant decrease of mean ( \pm SD) of composite equilibrium score, somatosensory ratio score between moderate or severe DPN and control healthy group $(p<0.05)$.

Table 2: Correlation of Composite Equilibrium Score (CES \%), somatosensory ratio score, visual ratio score and vestibular ratio score between four subgroups of diabetic patients ( $A$ to D) and control group.

\begin{tabular}{|c|c|c|c|c|c|}
\hline $\begin{array}{l}\text { SOT } \\
\text { Parameters }\end{array}$ & $\begin{array}{l}\text { Control } \\
\text { healthy } \\
\text { group }\end{array}$ & $\begin{array}{c}\text { A } \\
\text { (Diabetes } \\
\text { without PN) }\end{array}$ & $\begin{array}{c}\mathrm{B} \\
\text { (mild DPN) }\end{array}$ & $\begin{array}{c}\mathrm{C} \\
\text { (moderate } \\
\text { DPN) }\end{array}$ & $\begin{array}{c}\mathrm{D} \\
\text { (severe } \\
\text { DPN) }\end{array}$ \\
\hline Comparison & - & $\begin{array}{l}\text { A and } \\
\text { control }\end{array}$ & $\begin{array}{l}\text { B and } \\
\text { control }\end{array}$ & $\begin{array}{l}\mathrm{C} \text { and } \\
\text { control }\end{array}$ & $\begin{array}{l}\mathrm{D} \text { and } \\
\text { control }\end{array}$ \\
\hline Number & 30 & 16 & 17 & 13 & 11 \\
\hline Age (years) & $45.16 \pm 2.26$ & $45.37 \pm 1.73$ & $46.07 \pm 3.78$ & $53.55 \pm 3.16$ & $54.55 \pm 4.00$ \\
\hline $\begin{array}{l}\text { Disease } \\
\text { duration } \\
\text { (years) }\end{array}$ & - & $6.93 \pm 2.11$ & $9.23 \pm 1.20$ & $15.92 \pm 5.52$ & $23.72 \pm 3.19$ \\
\hline $\begin{array}{l}\text { Composite } \\
\text { Equilibrium } \\
\text { Score }\end{array}$ & $88.30 \pm 1.89$ & $\begin{array}{c}84.50 \pm 5.53 \\
(p>0.05)\end{array}$ & $\begin{array}{l}70.58 \pm 5.02 \\
\left({ }^{* *} \mathrm{p}<0.001\right)\end{array}$ & $\begin{array}{l}62.76 \pm 7.14 \\
\left({ }^{* *} p<0.001\right)\end{array}$ & $\begin{array}{l}41.00 \pm 7.81 \\
\left({ }^{* *} \mathrm{p}<0.001\right)\end{array}$ \\
\hline $\begin{array}{l}\text { SOM ratio } \\
\text { score }\end{array}$ & $0.91 \pm 0.22$ & $\begin{array}{c}0.89 \pm 0.05 \\
(p>0.05)\end{array}$ & $\begin{array}{c}0.57 \pm 0.11 \\
\left({ }^{* *} p<0.001\right)\end{array}$ & $\begin{array}{c}0.74 \pm 0.05 \\
\left({ }^{* *} p<0.001\right)\end{array}$ & $\begin{array}{c}0.41 \pm 0.07 \\
\left({ }^{* *} p<0.001\right)\end{array}$ \\
\hline $\begin{array}{l}\text { Visual ratio } \\
\text { score }\end{array}$ & $0.84 \pm 0.02$ & $\begin{array}{c}0.82 \pm 0.03 \\
(p>0.05)\end{array}$ & $\begin{array}{c}0.77 \pm 0.04 \\
(p>0.05)\end{array}$ & $\begin{array}{c}0.78 \pm 0.13 \\
(p>0.05)\end{array}$ & $\begin{array}{c}0.81 \pm 0.03 \\
(p>0.05)\end{array}$ \\
\hline $\begin{array}{l}\text { Vest. Ratio } \\
\text { score }\end{array}$ & $0.53 \pm 0.10$ & $\begin{array}{c}0.55 \pm 0.10 \\
(p>0.05)\end{array}$ & $\begin{array}{c}0.47 \pm 0.10 \\
(p>0.05)\end{array}$ & $\begin{array}{c}0.51 \pm 0.09 \\
(p>0.05)\end{array}$ & $\begin{array}{c}0.51 \pm 0.12 \\
(p>0.05)\end{array}$ \\
\hline
\end{tabular}

Non-Significant (NS) $p>0.05$; Significant $(\mathrm{S}){ }^{*} \mathrm{p}<0.05$; highly significant $\left.\mathrm{HS}\right){ }^{*} \mathrm{p}<0.001$ (ANOVA). 
Table 3: Composite Equilibrium Score (CES \%), somatosensory ratio score, visual ratio score and vestibular ratio score before and after training in subgroups of Diabetic patient with peripheral neuropathy (DPN).

\begin{tabular}{|c|c|c|c|c|c|c|}
\hline & \multicolumn{2}{|c|}{ Mild DPN } & \multicolumn{2}{|c|}{ Moderate DPN } & \multicolumn{2}{|c|}{ Severe DPN } \\
\hline & Before training & After Training & Before training & After Training & Before training & After Training \\
\hline Composite Equilibrium Score & $70.58 \pm 5.02$ & $86.35 \pm 4.97\left({ }^{* *} p<0.001\right)$ & $62.76 \pm 7.14$ & $60.84 \pm 11.29(p>0.05)$ & $41.00 \pm 7.81$ & $41.90 \pm 8.22(p>0.05)$ \\
\hline SOM ratio score & $0.57 \pm 0.11$ & $0.76 \pm 0.03\left({ }^{\star *} \mathrm{p}<0.001\right)$ & $0.74 \pm 0.05$ & $0.67 \pm 0.14 \quad(p>0.05)$ & $0.41 \pm 0.00$ & $0.41 \pm 0.08(p>0.05)$ \\
\hline Visual ratio score & $0.77 \pm 0.04$ & $0.78 \pm 0.05(p>0.05)$ & $0.78 \pm 0.13$ & $0.76 \pm 0.12(p>0.05)$ & $0.48 \pm 0.30$ & $0.49 \pm 0.30(p>0.05)$ \\
\hline Vest. ratio score & $0.47 \pm 0.10$ & $0.50 \pm 0.10(p>0.05)$ & $0.47 \pm 0.10$ & $0.49 \pm 0.09(p>0.05)$ & $0.43 \pm 0.17$ & $0.43 \pm 0.16(p>0.05)$ \\
\hline
\end{tabular}

In Table 3, there was a significant increase of mean $( \pm S D)$ of composite equilibrium score after treatment $(86.35 \pm 4.97)$ as compared to results before training $(70.58 \pm 5.02)(p<0.05)$ in mild DPN. Also, there was a significant increase of mean $( \pm S D)$ of the somatosensory ratio score after treatment $(0.76$ $\pm 0.03)$ as compared to results before training $(0.57 \pm$ $0.11, p<0.05)$ in the mild DPN.

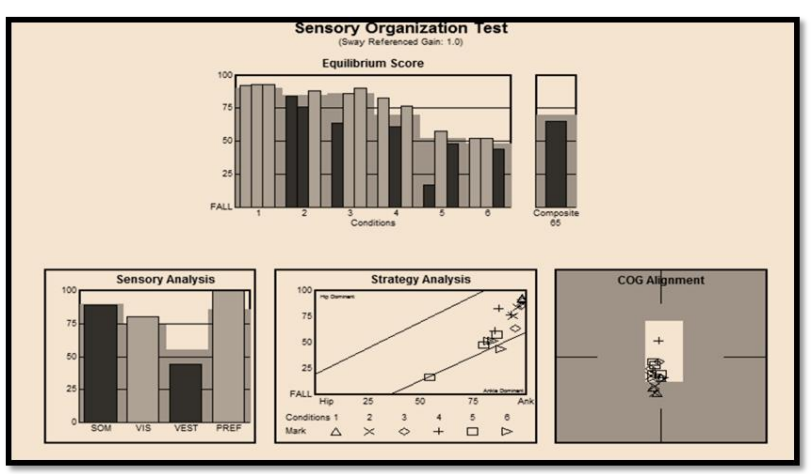

Figure 1: Sensory organization test with Composite Equilibrium Score (CES 55\%) before treatment in mild DPN.

However, there was a non-significant difference in visual ratio score, and vestibular ratio score before as compared to results after training $(p>$ 0.05 ) in the mild DPN. Moreover, in moderate and severe DPN, there was non-significant difference of mean $( \pm S D$ ) of composite equilibrium score (CES \%) and the sensory analysis scores after treatment as compared to results before training in moderate and severe DPN ( $p>0.05)$. Figures 1 and 2 showed sensory organization test, with composite equilibrium score (CES) before (CES 55\%) after (CES 82\%) treatment in mild DPN.

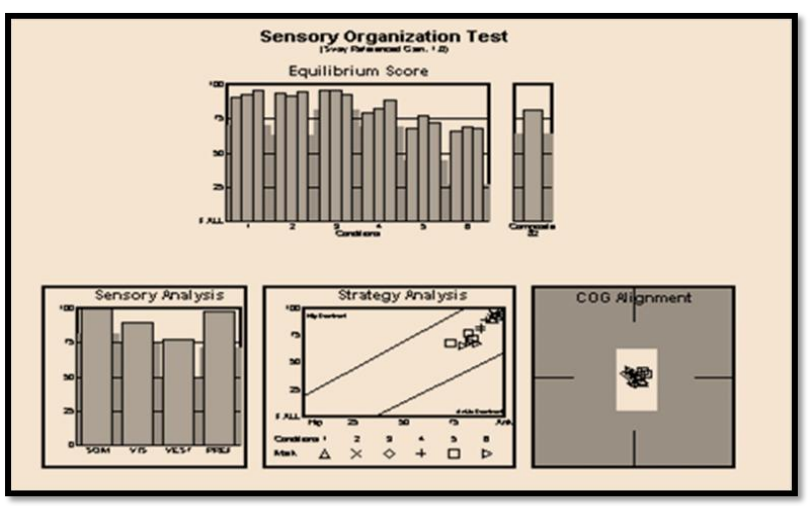

Figure 2: Sensory organization test with Composite Equilibrium Score (CES 82\%) after treatment in mild DPN.
Moreover, there were a significant correlation between composite equilibrium score and disease duration before training in the severe DPN $(r=0.368$, $\mathrm{p}<0.05$ ) as shown in Table 4.

Table 4: Correlations between Composite Equilibrium Score (CES), age and disease duration before training in severe DPN.

\begin{tabular}{lr}
\hline Variables & Composite equilibrium score in severe DPN \\
\hline Age & $r=0.088(p>0.05)$ \\
Disease duration & $r=0.368\left({ }^{*} p<0.05\right)$ \\
Creatinine & $r=0.041 \quad(p>0.05)$ \\
\hline Non-Significant (NS) $p>0.05 ;$ Significant ${ }^{*} p<0.05$; highly significant ${ }^{* *} p<0.001$.
\end{tabular}

\section{Discussion}

The postural control is a complex system that controls the orientation and balance of the body when it is in an upright posture [12]. Imbalance is commonly found in patients with polyneuropathy due to impaired proprioception and motor functions [13]. Severe disturbances of balance and gait can occur in proprioceptive afferent disorders and may correlate with the severity of neuropathy [14]. One common approach to examining postural control, especially in clinical settings is computerized dynamic posturography which assesses how well an individual integrates sensory information relevant for balance control [15].

In agreement with our results, some authors revealed that there were no significant differences in posturographic parameters between diabetic patients without neuropathy and the healthy control subjects. Computerized dynamic posturography showed that Type 2 diabetic patients with peripheral neuropathy have greater postural instability than those without neuropathy. A strong correlation of instability with peripheral neuropathy is present in diabetic patients. This result implies that peripheral neuropathy plays an essential role in the instability in type 2 diabetic patients [14]. Moreover, other authors revealed that diabetic patients with peripheral neuropathy demonstrate a relative deficit in their ability to maintain posture [8]. Some authors showed that type 2 diabetic patients with peripheral neuropathy exhibited an inability to maintain an upright posture [16].

Emam A etal reported that posture instability in type 2 diabetic patients with peripheral neuropathy reflects an impairment of the somatosensory system. The early detection of imbalance using dynamic posturography and achieving good glycaemic control 
may be of great help in the prevention of falls in such patients [17]. On the other hand, some authors revealed that dynamic posturography in IDDM may reflect the impairment of the somatosensory system, rather than a specific lesion of vestibular and/or visual modalities [5].

In disagreement with our results, our results showed that there were non-significant differences of balance parameters between diabetes without $\mathrm{PN}$ and healthy group. However, other authors showed that balance and gait are both impaired in people with diabetes. Subjects with diabetes had poorer balance during standing in diminished light compared to full light and no light conditions [18].

In agreement with our results, some author reported that a positive effect of visual feedbackbased balance training on fall incidence was found. In addition, they reported a reduced fear of falling and increased physical activity after a training period [19]. On the other hand, other author reported that following training, increased strength correlates highly with improved balance and decreased falls risk [20]. The data from other studies showed that an exercise regimen increases rapidly ankle strength and improvement of balance among older persons with mild to moderate PN [21]. Some author reported that of the training programs lead to the improvement in function and clinical balance measurements for the balance group and the significant decline in falls [22].

Morrison $\mathrm{S}$ et al. results show that following training of the type 2 diabetes group demonstrated improvements in balance, proprioception, lower-limb strength and consequently, decreased risk of falling. In addition, the benefits of exercise are not limited to muscle function rather, but impacting positively on sensory, motor and cognitive processes [21]. This decline in falls was reflected by improved proprioception and increased hamstring/quadriceps strength. While increasing physical activity can lead to enhanced joint proprioception [22].

In agreement with our results, Oppenheim etal found that the patients with severe neuropathy were may be related to the relatively longer duration of their illness [6]. On the other hand, older individuals with type 2 diabetes often exhibit greater impairments in posture. Consequently, older individuals with the type 2 diabetes group were at greater falls risk. Thus, increasing age, previous falls history, increased postural sway, and presence of diabetes are major risk factors for falling [23]. Other data show that a strong association exists between the presence of distal symmetrical polyneuropathy and illness duration, $\mathrm{HbA} 1 \mathrm{c}$ or smoking [24]. Emam A et al. reported that Posture instability in type 2 diabetic patients with peripheral neuropathy reflects an impairment of the somatosensory system; also, poor glycaemic control resulted in more posture instability [16].

The mechanisms of peripheral neuropathy leads to postural instability are complex. Imbalance is commonly found in patients with polyneuropathy due to impaired proprioception and motor functions [13]. Morrison $S$ etal results show that imbalance resulted in impacting on falls and from deficits of sensory (impaired proprioception), motor (lower-limb strength weakness) and cognitive processes [21]. Grewal GS etal (2013) reported that Individuals with diabetic peripheral neuropathy frequently experience concomitant impaired proprioception and postural instability [25].

The presence of postural instability in poorlycontrolled diabetics could be associated with severe nerve damage due to long-standing hyperglycaemia. Hyperglycaemia is associated with the glycosylation of antioxidant enzymes that make the oxygen free radical scavenger system less efficient; the resulting high oxidative stress plays an important role in the pathogenesis of diabetic microangiopathy [26]. Moreover, chronic hyperglycaemia is associated with the activation of the polyol pathway and the accumulation of sorbitol and fructose in nerve cells, which lead to $(\mathrm{Na}+/ \mathrm{K}+)$-ATPase dysfunction [31] and subsequent demyelination of the peripheral nerves [27].

In conclusion, computerized dynamic posturography is an important quantitative tool in the assessment of posture instability and allows for early disclosure of the failure of the postural control system. The impairment of posture stability reflects an impairment of the somatosensory system. The early detection of posture instability using computerized dynamic posturography and achieving good diabetic control could be of great help in the prevention of fallrelated morbidity and mortality in diabetics with peripheral neuropathy.

\section{Acknowledgements}

We are grateful to all the staff at the diabetes and balance clinics for their support and all the patients who participated in this study.

\section{References}

1. Greene DA, Stevens MJ, Feldman EL. Diabetic neuropathy: scope of the syndrome. Am J Med. 1999; 107 (2B):2S-8S.

2. Arezzo JC. New developments in the diagnosis of diabetic neuropathy. Am J Med. 1999; 107 (2B):9S-16S.

3. Boulton AJ, Malik RA, Arezzo JC, Sosenko JM. Diabetic somatic neuropathies. Diabetes Care. 2004; 27(6):1458-86.

4. Cohen JA, Jeffers BW, Faldut D, Marcoux M, Schrier RW. Risks for sensorimotor peripheral neuropathy and autonomic neuropathy in non-insulin-dependent diabetes mellitus (NIDDM). Muscle Nerve. 1998; 21(1):72-80.

5. Di Nardo W, Ghirlanda G, Cercone S et al. The use of dynamic posturography to detect neurosensorial disorder in IDDM without clinical neuropathy. J Diabetes Complications. 1999; 13(2):79-85.

6. Oppenheim V, Kohen-Raz R, Alex D et al. Postural 
characterestics of diabetic neuropathy. Diabetes Care. 1999; 22(2):28-33.

7. Maurer MS, Burcham J, Cheng H. Diabetes mellitus is associated with an increased risk of falls in elderly residents of a long-term care facility. J Gerontol A Biol Sci Med Sci. 2005; 60(9):1157-62.

8. Uccioli L, Giacomini PG, Monticone G, Magrini A, Durola L, Bruno E, Parisi L, Di Girolamo S, Menzinger G. Body sway in diabetic neuropathy. Diabetes Care. 1995; 18(3):339-44.

9. Dyck PJ, Melton LJ III, O'Brien PC, Service FJ: Approaches to improve epidemiological studies of diabetic neuropathy: insights from the Rochester Diabetic Neuropathy Study. Diabetes. 1997; 46 (Suppl 2):5-8.

10. Kandel ER, Schwartz JH, Jessel TM. Principles of neurology science. In: Dumitru D. Electrodiagnostic Medicine. New York: McGraw-Hill, 2000: P 730-1.

11. Chaudhry H, Findley T, Quigley KS, et al. Measures of postural stability. J Rehabil Res Dev. 2004; 41 (5):713-20.

12. Macpherson JM, Fung J, Jacobs R. Postural orientation, equilibrium, and the spinal cord. Adv Neurol. 1997; 72:227-32.

13. Voorhees RL. Dynamic posturography findings in central nervous system disorders. Otolaryngol Head Neck Surg. 1990; 103:96-101.

14. Lee $\mathrm{GH}$. Computerized dynamic posturography and diabetic peripheral neuropathy. J Korean Geriatr Soc. 2003; 7(4):342-50.

15. Rosengren KS, Rajendran K, Contakos $\mathrm{J}$ et al. Changing control strategies during standared assessment using computerized dynamic posturography with older women. Gait Posture. 2007; 25(2):215-21.

16. Yamamoto R, Kinoshita T, Momoki T, Arai T, Okamura A, Hirao $\mathrm{K}$, Sekihara H. Postural sway and diabetic peripheral neuropathy. Diabetes Res Clin Pract. 2001;52(3):213-21.

17. Emam AA, Gad AM, Ahmed MM, Assal HS, Mousa SG. Quantitative assessment of posture stability using computerised dynamic posturography in type 2 diabetic patients with neuropathy and its relation to glycaemic control. Singapore Med J. 2009; 50(6): 614.

18. Petrofsky JS, Cuneo M, Lee S, Johnson E, Lohman E. Correlation between gait and balance in people with and without Type 2 diabetes in normal and subdued light. Med Sci Monit. 2006 Jul;12(7):CR273-81.

19. Sihvonen S, Sipilä S, Taskinen S, Era P. Fall incidence in frail older women after individualized visual feedback-based balance training. Gerontology. 2004; 50(6):411-6.

20. Barnett A, Smith B, Lord SR, Williams M, Baumand A. Community-based group exercise improves balance and reduces falls in at-risk older people: a randomised controlled trial. Age and Ageing. 2003; 32(4):407-14.

21. Lindeman $E$, Leffers $P$, Spaans $F$ et al. Strength training in patients with myotonic dystrophy and hereditary motor and sensory neuropathy: a randomized clinical trial. Arch Phys Med Rehabil. 1995; 76(7):612-20.

22. Nitz JC, Choy NL. The efficacy of a specific balance-strategy training programme for preventing falls among older people: a pilot randomised controlled trial. Age and Ageing. 2004; 33: 52-8.

23. Schwartz AV, Hillier TA, Sellmeyer DE et al. Older Women with Diabetes Have a Higher Risk of Falls: A prospective study. Diabetes Care. 2002; 25(10):1749-54.

24. Tamer A, Yildiz S, Yildiz $\mathrm{N}$ et al. The prevalence of neuropathy and relationship with risk factors in diabetic patients: a single-center experience. Med Princ Pract. 2006; 15(3):190-4.

25. Grewal GS, Sayeed R, Schwenk M, Bharara M, Menzies R, Talal TK, and Armstrong DG, Najafi B. Balance rehabilitation: promoting the role of virtual reality in patients with diabetic peripheral neuropathy. J Am Podiatr Med Assoc. 2013; 103(6):498-507.

26. Head KA. Peripheral neuropathy: pathogenic mechanisms and alternative therapies. Altern Med Rev. 2006; 11:294-329.

27. Raccah D, Coste T, Cameron NE, et al. Effect of the aldose reductase inhibitor tolrestat on nerve conduction velocity, $\mathrm{Na} / \mathrm{K}$ ATPase activity, and polyols in red blood cells, sciatic nerve, kidney cortex and kidney medulla of diabetic rats. J Diabetes Complications. 1998; 12:154-62. 